\title{
HEGEL, SUCESOR DE SCHELLING; SCHELLING, SUCESOR DE HEGEL
}

José Antonio Pardo*

RESUMEN: El autor precisa con claridad la relación entre Schelling y Hegel, que -sostiene- ha sido malentendida. El primero, bajo la "filosofía de la identidad", acomoda tanto su propio pensamiento como el de Hegel, de tal manera que Hegel no será sino un "Hegel de Schelling".

soes

ABSTRACT: The author clearly establishes the relationship between Schelling and Hegel which, according to him, has been misunderstood. The former, in his identity philosophy, incorporates his theory as well as that of Hegel in such a way that it becomes a "Schelling's Hegel."

PALABRAS ClAVE: Hegel, Schelling, filosofía positiva, filosofía de la identidad, ser, existencia. KEYWORDS: Hegel, Schelling, positive philosophy, identity philosophy, being, existence.

RECEPCIÓN: 18 de marzo de 2010.

APROBACIÓN: 22 de abril de 2010.

* Universidad Iberoamericana, UIA. 
La reproducción total o parcial de este artículo se podrá hacer si el ITAM otorga la autorización previamente por escrito. 


\section{HEGEL, SUCESOR \\ DE SCHELLING; SCHELLING, SUCESOR DE HEGEL}

1. La mayoría de los manuales de historia de la filosofía ponen las cosas muy fáciles: el brillo de la obra de Kant dejó deslumbrado a casi todo mundo, incluyendo a una joven generación de pensadores alemanes que decidió proseguir el camino desde donde aquél lo había dejado, recorrerlo hasta el final, hasta llegar inclusive a besar el absoluto. Son muchos los nombres, pero destacan tres, los genios del idealismo alemán, cada uno sucesor del anterior: Fichte, Schelling, Hegel. Kant sería la reja, el sembrador de la simiente, el hombre que indicó el camino por venir, el profeta clarividente. Fichte, el pimpollo perfumado, el discípulo excelente, el andador decidido de los primeros pasos. Schelling, el arbusto prodigioso, la agudeza infinita, el explorador aventurero. Y Hegel, el fruto maduro, el cuajo espeso, el sello rutilante de la obra entera. El fin de la historia, y para espectáculo de los siglos por venir, la admirable catedral del sistema. Después de eso, las desgarraduras, las grietas, los grandes críticos: Marx, Kierkegaard, Nietzsche, la corrosión de los cimientos del enorme templo del saber absoluto por obra de la sospecha.

Pienso de este cuadro dos cosas. Una, que en realidad está incompleto. No se incluyen algunos detalles de la relación entre Hegel y Schelling que determinarán de manera decisiva el curso posterior de la historia del pensamiento. La relación entre Hegel y Schelling no se reduce, ni por asomo, a que éste haya sido el mero antecedente de aquél. Si bien Hegel comienza siendo schelliniano al despuntar el alba del siglo XIX, 
ya para la publicación de la Fenomenología del Espíritu, la ruptura entre él y Schelling es irreversible. Empero, es frecuente encontrar que toda la obra de Hegel es interpretada como si fuera una mera suerte de prolongación, sin solución de continuidad, de la filosofía de la identidad de Schelling. No se han mostrado aún suficientemente las nefastas consecuencias que, para la justa interpretación de este filósofo, ha tenido "esta asociación con el punto de vista de Schelling”, asociación que "iba a colorear en alguna medida la reputación de Hegel durante el resto de su vida"9 y después de ésta.

La otra cosa que pienso es que, si bien es medianamente bien conocido, sobre todo gracias a Heidegger, los manuales de historia de la filosofía no suelen dar cuenta de que Schelling, quizá a partir de 1815, trueca su propia postura, abandona la filosofía de la identidad y se encamina, después de una tenaz crítica contra tal filosofía, hacia lo que él mismo llamará "filosofía positiva". Lo notable es que bajo el rubro "filosofía de la identidad”, Schelling no sólo acomoda su propio pensamiento anterior, sino también el de Hegel. Es Schelling quien más va a contribuir a que se asocie el nombre de Hegel a filosofía de la identidad. Es decir, quien más contribuyó a que Hegel sea asociado con el punto de vista de Schelling es el mismo Schelling.

No es extravagante la hipótesis de que fue él quien dibujó la imagen de Hegel contra la cual los "post-hegelianos" dirigieron sus críticas. Basta con asomarse al Post-Scriptum de Kierkegaard, y recordar que éste, junto con Engels, Feuerbach y Bakunin, asistieron a los cursos de Schelling en Berlín, para darse cuenta de que en la célebre disputa trabada entre Kierkegaard y Hegel, corresponde no tanto a Kierkegaard y a Hegel como a Kierkegaard y al "Hegel de Schelling".

2. Es fama que Schelling y Hegel, junto con el inspirado Höderlin, hicieron migas cuando asistieron al Seminario de Tubinga. También que la amistad entre Hegel y Schelling se va a quebrar definitivamente debido a que, en la Fenomenología, su autor abandona los puntos de vista de Schelling, que hasta antes de ello había defendido públicamente. Schelling se sentirá traicionado y no perdonará nunca. Hegel muere en

${ }^{9}$ Terry Pinkard, Hegel, 2002 , Madrid, Acento, trad. de Carmen García-Trevijano, p. 159. 
1831, dejando vacante su cátedra en la Universidad de Berlín. Casi diez años después sube Federico IV al trono prusiano. Se ha repetido hasta la saciedad que Hegel fue el ideólogo oficial de la monarquía prusiana y que llegó a enseñar que el Estado prusiano era la encarnación de Dios en la Historia. No sólo es indocumentable lo último -en ningún lugar Hegel sostiene eso ni lo sugiere-, sino que, por el contrario, fue un pensador demasiado incómodo, tanto para Federico III como para su hijo, Federico IV, y para toda la corte. Por esto, en 1841, muy pocos días después de que hubo ascendido al trono, el nuevo emperador decidió poner orden en su universidad y pintarle la raya a los hegelianos: contrata a Schelling para que ocupe la cátedra que fuera la de Hegel, mediante un contrato en el que quedaba estipulado el encargo de "extirpar la simiente del dragón del racionalismo hegeliano de las mentes de la juventud prusiana". ${ }^{10}$ Schelling cumplirá el encargo cabalmente, dejará inoculado el virus antihegeliano en la cabeza de los asistentes a sus cursos, y el virus medrará hasta infectar toda la filosofía del siglo XX. ¿Cuál es esta imagen de Hegel pintada por Schelling? Antes de responderlo, definamos cuál fue el material con el que Schelling pintó el cuadro.

3. La sola mención del nombre "idealismo" convoca una tormenta de equívocos. Incluso en algunos casos llega a operar ese nombre como señal de reprobación. No es raro leer alguna crítica al idealismo que vaya en el sentido de que éste sea un tipo de pensamiento que explícitamente se declare desinteresado de la realidad. Recuerdo haber leído en Jacques Maritain, en una especie de testamento intelectual, Le Paysanne de la Garonne, algo semejante a que los filósofos idealistas se llamaban filósofos en sentido equívoco, y que más bien debían ser llamados "ideósofos", por ser más amantes de las ideas que de la "realidad" y, por ende, de la sabiduría. Marx, por su cuenta, llama a Hegel ideólogo, porque según él, el alemán en vez de concentrarse en analizar la realidad, lo que hace es discurrir acerca de lo que "corre ante sí en su propio pensamiento". ${ }^{11}$ Es decir, de acuerdo con Marx, el logos de Hegel,

${ }^{10}$ John Edgard Toews, Hegelianism. The Path toward dialectical humanism, 1805-1841, 1985, Cambridge, Cambridge Universtity Press, p. 254.

${ }^{11}$ Das Elend der Philosophie, en Marx-Engels Werke IV, 1972, Berlín, Dietz Verlag, p. 129. 
JOSÉ ANTONIO PARDO

en vez de ser un logos sobre la realidad, es un logos sobre las "meras ideas": por eso ideología. Éste no es, sin embargo, el sentido que tiene la expresión "idealismo", por lo menos en Fichte y en Hegel, aunque por lo demás, Schelling contribuirá a que se piense que sí.

Bernabé Navarro comenta al respecto que muy a menudo se ha malentendido la tesis fundamental del idealismo alemán:

Pues numerosos autores han opinado que niega la realidad, es más, la objetividad del mundo [...] Pero no se pensó al respecto que, de lo único que se trata propiamente, es de la manifestación o aparición del mundo en el Yo, y sólo en él [...] Que de lo que está, es o sucede afuera, absolutamente no se puede saber nada, pues el saber o el conocimiento se realiza justamente en el saber mismo, mediante las funciones y estructuras del saber. ${ }^{12}$

La disputa entre realismo e idealismo, en términos de si el conocimiento es capaz de trascenderse o no a sí mismo hacia una "realidad exterior", es una disputa vacía. No tiene sentido la expresión "fuera de la mente" o "fuera del pensamiento", porque ni la mente ni el pensamiento son cajas que tuvieran un dentro y un afuera. Si se prescinde de la metáfora y se sostiene que con realidad se quiere decir "lo que no es la mente" o "lo que es distinto de la mente" habría que admitir, por ende, que la mente no es real, cosa que no admiten quienes así definen. Por lo demás, aunque se concediera que la mente, en efecto, no es real, "realidad" quedaría definida al cabo, de manera tautológica o nula: si la mente no es real entonces no es nada, de suerte que el significado de realidad sería lo distinto de lo no real.

El conocimiento, inevitablemente, es siempre en la mente, entendiéndose por mente lo que se guste y mande. El idealismo no consiste en negar la "realidad exterior", cosa imposible porque de hecho "realidad exterior" carece de significado. El idealismo no niega la realidad exterior, sino que "realidad exterior" sea expresión significativa. Por lo demás, negar que la expresión "fuera de la mente" carezca de significado no es la postura que define al idealismo en sentido estricto. Existe otro tipo

${ }^{12}$ El desarrollo fichteano del idealismo trascendental de Kant, 1975, México, UNAM-FCE, p. 143. 
de disputa, que en algún sentido guarda relación de proporción con aquella entre idealismo y realismo, pero que sí tiene sentido, a saber, entre racionalismo y empirismo. Es la disputa que dividirá las posturas de Hegel y del segundo Schelling, pero es irrelevante para definir la esencia del idealismo alemán.

La razón por la cual se usa la palabra "idealismo" para referirse a Fichte, al primer Schelling y a Hegel es que estos tres autores se pronuncian de manera categórica en favor de la tesis que afirma el primado de lo práctico sobre lo teórico. En seguida un par de buenos testimonios espigados de las páginas de Fichte: "Afirmamos una relación de la ley moral [Sittengesetzes] con la razón teórica, un primado de la primera sobre la última, tal como Kant lo expresa". "Nuestro idealismo no es dogmático, sino práctico: no determina lo que es, sino lo que debe ser". ${ }^{14}$

Debe recordarse que Kant utiliza la expresión "idea" [Idee] en sentido muy restringido y muy técnico. Para definirla, hace que su memoria y la del lector se remonten hacia la antigua Ática: "Platón dio, por medio de su idea suprema, con todo lo que es práctico, esto es, con la libertad, la cual depende, por su lado, de conocimientos que son auténticamente productos de la razón". ${ }^{15}$ De las ideas de la razón -“alma, mundo y Dios"-, escribe Kant que su contenido sale fuera del ámbito de la experiencia posible, de modo que ocuparse de ellas resulta una ociosidad, salvo que se las considere como en realidad debe considerárselas, como determinaciones prácticas. ${ }^{16}$

Ahora bien, Fichte pretende ir más allá de Kant. No solamente afirma la prioridad del uso práctico de la razón en relación con el uso teórico, sino que además sostiene que la razón, en sí misma y en cuanto tal, es práctica. Si hay algo que Fichte, tanto como Hegel, censura persistentemente de la obra de Kant, es que en ella no haya tomado en cuenta suficientemente el carácter práctico del pensamiento, en particular al momento de querer dar cuenta de sí mismo: "subsiste el profundo mérito

${ }^{13}$ System der Sittenlehre nach dem Principiem der Wissenschaftlehere, en Johann Gottlieb Fichte's sämtliche Werke, 1845, Berlín, editadas por J.H. Fichte, cuarto volumen, segundo tomo, Zur Rechts und Sittenlehre, Verlag von Veit und Comp., p. 165

${ }^{14}$ Grundlage der gesammten Wissenschaftslehre, en ibid, primer volumen Zur theoretischen Pilosophie, p. 156.

${ }^{15}$ Kritik der reinen Vernunft, 1966, B 370, Stuttgart, Suhrkamp, p. 395.

${ }^{16}$ Ibid., B 827-828, p. 810. 
JOSÉ ANTONIO PARDO

de la filosofía fichteana de haber recordado [contra Kant] que las determinaciones del pensamiento se han de demostrar en su necesidad, que esencialmente han de deducirse ${ }^{\text {" }}{ }^{17}$ Es decir, Kant, en vez de haber procedido a deducir la forma determinada del pensamiento según el carácter determinante del mismo pensamiento, lo habría hecho a partir de un hallazgo empírico. "Es sabido que la filosofía kantiana ha terminado por hallar muy fácilmente las categorías [...] De manera feliz se ha encontrado en la lógica ordinaria [gewöhnlichen Logik] con los distintos tipos de juicios, los cuales se le han dado ya empíricamente [...] Enumerar las distintas y ya decididas maneras de juzgar proporcionará tantas otras y distintas determinaciones del pensamiento". ${ }^{18}$

Así como Kant reprocha a Aristóteles que éste no haya confeccionado su lista de categorías conforme a pensamiento definido, sino que las hubiera "recogido" tal como se las fue encontrando, ${ }^{19}$ Fichte y Hegel reprochan a Kant haber hecho lo mismo. Si bien Kant tiene consigo ese principio cuya ausencia afea en Aristóteles, lo cierto es que no es en virtud de tal principio que elabora su tabla de categorías, la cual es más bien urdida según otro principio, que no es sino el uso empírico de los juicios, principio que según Hume mismo, es incapaz de brindar ninguna regla de necesidad. Kant asume y reconoce la validez de la crítica humeana, a la vez que recurre al pensamiento (las categorías a priori) para hacer descansar sobre él la necesidad de los juicios científicos. Sin embargo, a la hora de querer dar cuenta, de querer justificar "científicamente" la forma determinada que él reconoce en el pensamiento (en las categorías), recurre a esa experiencia empírica que anticipadamente había dejado descartada, y no al principio descubierto por él mismo. El pensamiento queda siendo principio determinante en relación con el objeto, pero no en relación consigo mismo, no en relación con su propia forma. Pero si el carácter determinante del sujeto es la garantía de objetividad del objeto, entonces al permanecer al margen de sí mismo dejaría sin garantizar, por ende, la objetividad de la concepción que tiene de sí mismo. Paradójicamente la concepción kantiana

${ }^{17}$ Hegel, op. cit., ibid.

${ }^{18}$ Enzyklopädie der philosophischen Wissenschaften I, , 1986, Frankfurt, § 42, Suhrkamp, p. 117.

${ }^{19}$ Kritik der reinen Vernunft, B107, op. cit., p. 151. 
del sujeto carece de objetividad, según Hegel, por desatender para sí misma su propio carácter subjetivo o práctico.

Detengámonos en esta asociación entre subjetivo, determinante y práctico. La tesis que afirma la primacía de la razón práctica sobre la teórica parece moverse en las antípodas de lo que enseñó Aristóteles, pues éste afirma explícitamente que la actividad teórica es "la mejor". Empero, la razón que da Aristóteles para convencernos de ello es que la actividad teórica es "la única que se ama por sí misma, pues de ella no se genera nada distinto que el teorizar, en tanto que en la práctica procuramos más o menos algo además de la práctica", ${ }^{20}$ afirmación que parece darse de cachetadas con otras en que afirma que la actividad práctica es aquella que es fin en sí misma, ${ }^{21}$ salvo que caigamos en la cuenta de que, en realidad, Aristóteles estima que la actividad teórica es la forma suprema de praxis, la praxis perfecta, y es porque vemos también que "el filósofo" define la praxis perfecta en contrastación con el movimiento, de modo que en realidad termina asimilando el concepto de actividad práctica al de actus purus, que a su vez es el del pensamiento que se piensa a sí mismo.

La tesis que sostiene que la razón es práctica afirma, también, que la razón es ser en acto [energeia], y que sólo en cuanto que tal es fuente de conocimiento de relaciones de necesidad: "La necesidad real es necesidad determinada [...] Esta determinidad [Bestimmtheit] en su primera simplicidad es ser en acto [Wirklichkeit]", escribe Hegel. ${ }^{22}$ En resumidas cuentas, la tesis del idealismo es que el comienzo de la ciencia debe ser la consideración del sujeto "en cuanto que actividad [kata ten energeian]". Pero de qué tipo de praxis o actividad se trata hablaremos enseguida. ${ }^{23}$

${ }^{20}$ Ética Nicomaquea, 1983, México, UNAM, 1177 b 3-4, pp. 252-3.

${ }^{21}$ Met. 1048 b 22-23, en Aristotelis Metaphysica, 1969, Oxford, Oxford University Press, pp. 184-5.

${ }^{22}$ Wissenschaft der Logik II, Frankfurt, Suhrkamp, 1986, p. 213.

${ }^{23}$ Escribe Marx: "El principal defecto de todo el materialismo anterior es que lo dado (Gegenstand), la realidad y la sensibilidad son considerados sólo bajo la forma del objeto (Form des Objekts) o de intuición (Anschauung), pero no como actividad (Tätigkeit) sensorial humana, ni como Praxis, ni subjetivamente. De ahí que el lado activo se desarrollara abstractamente en la contraposición del idealismo con el materialismo-idealismo que naturalmente no conoce en realidad la actividad sensible como tal" (Thesen über Feuerbach, en Marx-Engels Werke III, p. 6). Marx interpreta parcialmente bien el propósito del idealismo, pero pierde de vista la razón por la cual considerar el lado activo de la racionalidad. Es posible alegar carácter activo en la sensibilidad, pero no de actividad demostrativa fundamental, que es lo que importa. 
JOSÉ ANTONIO PARDO

4. Aristóteles defendía que lo que distingue al saber científico de los otros tipos de saberes es su carácter necesario o demostrativo. Dicha necesidad estriba en dos cosas. La primera en que la proposición científica sea deducida de un saber previo: "razonamiento [sillogismòs] es una proposición [lógos] en la que, puesta una cosa, necesariamente suceda [symbaínei] otra cosa que la establecida por aquella proposición". ${ }^{24}$ La segunda, que el mentado saber previo del cual se deduce la proposición científica, también sea científico, necesario. Puede ser esto último si, a su vez, es deducible de un saber previo. Pero no es posible que estos saberes previos se multipliquen infinitamente. De modo que habría que admitir que la ciencia verdadera se basa, en último término, en verdades primeras e inmediatas [proton kai ameson], ${ }^{25}$ es decir, en verdades cuya calidad de tales no depende de ninguna mediación, de ningún "término medio" que las enlace necesariamente con una verdad anterior.

Damos de frente, entonces, con una especie de antinomia: el saber científico, para ser necesario, debe poseer el carácter necesario que otorga el razonamiento demostrativo, y además estar fundado en premisas necesarias; pero es imposible demostrar todo, ${ }^{26}$ de suerte que inevitablemente habrá que admitir por lo menos una premisa no demostrada (inmediata), una premisa que carezca, por ende, de ese carácter de necesidad que define a la ciencia. Salvo que se apele a una verdad necesaria e inmediata a la vez. Lo malo de esto último es que necesidad e inmediatez parecen ser conceptos excluyentes: parece que el único sentido que puede tener "necesario" es diciéndose de ese enlace entre las premisas y la conclusión. Al afirmar esto último no pretendo excluir de un plumazo el concepto de necesidad metafísica, ni me comprometo

${ }^{24}$ Anal. Pr. 24b 18-20, en Erste Analytik. Zweite Analytik, 1998, Hamburg, Felix Meiner, p. 4. "Est syllogismus oratio, in qua quibusdam positis necesse est aliud evenire ab his et propter haec": "El silogismo es la oración en la que, puestas ciertas cosas, es necesario que algo distinto suceda a partir y por esas cosas que han sido puestas" (Vid. William of Sherwood, Introducciones in Logicam, 1995, Hamburg, Felix Meiner, , III 5-6, p. 58; Petrus Hispanus, Tractatus IV, 2, México, UNAM, 1986, p. 39; Juan de Santo Tomás, Ars Logica. Prima Pars: Summula, 1986, México, UNAM, III, IV, 277, p. 106).

${ }^{25}$ Anal. Post. 71b 21-22 en Ibid., p. 314.

${ }^{26}$ Met. 1006 a 9, op. cit., p. 67. 
con la tesis que dice que carece de sentido la expresión "ente (cuyo ser es) necesario", sólo digo que cualquier saber inmediato, inclusive el saber acerca del ente (cuyo ser es) necesario, no es necesario por carecer de la mediación que lo hace necesario. ${ }^{27}$

La referencia a una verdad primera e inmediata es sólo la expresión de una conclusión paradójica: es necesario que el saber no sea necesario. En tanto no se resuelva la paradoja, la referencia a una verdad primera permanecerá nula, será equivalente a la referencia a "algo dado" que, empero, no es conocimiento. Escribe Sellars a propósito:

Si tenemos en mente que el meollo de la categoría epistemológica de lo dado es explicar la idea de que el conocimiento empírico depende, como de un fundamento, de un conocimiento no-inferencial, habríamos de experimentar un sentimiento de sorpresa al notar que, de acuerdo con los defensores de los datos sensibles, son los particulares los que son sentidos. Pero lo que es conocido, aun en el caso de un conocimiento no-inferencial, es hechos más que particulares, asuntos de la forma algo siendo así o asá o algo manteniendo cierta relación con algo más. De modo que podría parecer, entonces, que el sentido de contenido sensible no puede constituir conocimiento, ni inferencial ni no inferencial. ${ }^{28}$

5. Schelling encara el problema del comienzo de la ciencia siendo apenas un zagal. A poco de haber computado sólo veinte años de vida, en 1795, este niño prodigioso entrega a la imprenta un opúsculo denominado Del yo como principio de la filosofía o sobre lo incondicionado en el saber humano, en que discurre del siguiente modo:

O nuestro saber carece de realidad, es un eterno ciclo, un constante transcurrir recíproco de todas las proposiciones particulares una a otra, un caos $[\ldots]$ o debe existir un punto último de realidad $[\ldots]$ del que

${ }^{27}$ No está de más distinguir, así como Tomás de Aquino distingue, un doble sentido de ser "per se notum": "secundum se" y "quoad nos", ser necesario "secundum se" y "quoad nos" (Cfr. De Veritate q. 10, a. 12, en S. Thomae Aquinatis Quaestiones Disputatae I, 1949, Turín-Roma, Marietti, p. 219).

${ }^{28}$ Wildrid Sellars, "Empiricism and the Philosophy of Mind", en Willem A. de Vries y Timm Triplett, Knowledge, Mind and the Given, 2000, Indianapolis, Hackett Publishing Company, p. 206. 
JOSÉ ANTONIO PARDO

proceda todo cuanto da forma y consistencia a nuestro saber [...] Si algo como el saber existe, debe también existir un saber al que no se llegue mediante otro saber [...] que contenga el fundamento real de todo nuestro saber [...] Si debiéramos pensar otro saber para poder llegar a ese saber, entonces aquél sería más elevado que éste, lo cual es contradictorio; para alcanzar lo supremo no preciso nada más que de lo supremo mismo. ${ }^{29}$

El saber que depende de otro es un saber condicionado, el saber que no depende de otro, sino sólo de sí mismo, es el saber incondicionado. En cuanto tal, no podría estar condicionado por nada distinto de sí, de manera que no cabe suponer una realidad distinta al pensamiento sobre la cual éste ejerciera su actividad. El pensamiento incondicionado debe ser, él mismo, su propia realidad; debe ser la identidad entre pensamiento y realidad, entre sujeto y objeto.

¿Dónde buscar este saber? Sostiene Schelling que ni en el objeto ni en el sujeto. "Porque el sujeto sólo es pensable en relación con un objeto, y el objeto sólo en relación con un sujeto, ninguno de los dos puede contener lo incondicionado, pues ambos se condicionan mutuamente". ${ }^{30}$ Que no se pueda buscar en el objeto implica que lo incondicionado "debe yacer fuera de la esfera de lo demostrable objetivamente, [que lo incondicionado] contiene un ser que antecede todo pensar", ${ }^{31}$ de modo que es necesario apelar a una especie de saber de otra índole, a saber, la intuición. No la intuición sensible, porque ésta inevitablemente supone un objeto, sino una "intelectual". Notemos de una vez, aunque por lo demás sea muy conocido, que será este recurso a la intuición intelectual el que Hegel rechazará ásperamente en la Fenomenología. Aunque también debamos destacar que, bajo el famoso motivo de la intuición, hay uno más profundo, la verdadera raíz del desacuerdo entre los dos.

Apelar a la intuición siempre será un recurso problemático, sobre todo porque inevitablemente habrá de tener que ser justificada, tanto su existencia como la índole de su contendido, pero en términos no intuitivos. A final de cuentas, los libros de Schelling no abastecen

${ }^{29}$ Vom Ich als Princip der Philosophie oder ubre das Unbedingte im menschlichen Wissen, $\S$ 1, en Schelling Werke I, 1958, München, T.H. Beck'sche, pp. 86-87.

${ }^{30}$ Ibid. $\S 2$, p. 89.

${ }^{31}$ Ibid. § 3, p. 91. 
al lector de intuiciones, sino de discursos, argumentaciones, conceptos y saberes, por más que dichos discursos, argumentaciones, conceptos y saberes se presuman fundados en una intuición previa o pretendan hacer referencia a ella. Es enormemente paradójico apelar a la intuición, pues resulta imposible de evaluar, y aun exponer, el contenido de un pensamiento que apele a la intuición en términos intuitivos. Pero la tónica de la obra temprana de Schelling, más allá de la intuición, que opera sólo como un nombre o referencia abstracta, es el concepto de identidad. Es la identidad lo que Schelling sugiere ser el punto de partida de la ciencia; pero no se trata de una sugerencia que pretenda quedar anclada en la sola mención, pues es advertible el esfuerzo denodado puesto por este filósofo para ir mostrando cómo del concepto de identidad se va orgánicamente deduciendo prácticamente todo, la naturaleza y la conciencia. He aquí, enseguida, un elocuente texto:

La organización dinámica del universo es deducida [abgeleitet], pero no los andamiajes [Gerüste] mismos. Toda organización supone la evolución del universo desde un producto originario [ursprünglichen Produckt], una caída [Zerfallen] de dicho producto en siempre nuevos productos. El fundamento de esta caída infinita debe haber sido constituido en la naturaleza por una dualidad originaria, y esa escisión [Entzweiung] debe ser vista como surgida en una identidad originaria [ursprünglicher Identischen]. ${ }^{32}$

Esos andamiajes son el absoluto como identidad, y la ciencia, entonces, el esfuerzo por reconocer que el fundamento de lo real es la identidad de todo con el todo.

6. Hegel se instala en Jena durante el cambio de siglo y publica muy prontamente la Diferencia entre los sistemas de filosofía de Fichte y Schelling, texto en que se adhiere al punto de vista de su amigo, y en que logra expresar de manera muy clara y condensada dicho punto de vista: "El principio de identidad es el principio absoluto del sistema entero de Schelling [...] La identidad no se pierde en las partes, y aún

${ }^{32}$ Schelling, Erster Entwurf eines System der Naturphilosophie für Vorlesungen, en Ibid., II, p. 261. 
JOSÉ ANTONIO PARDO

menos en el resultado, [de modo que] la superación de la escisión queda asentada como tarea formal de la filosofía". ${ }^{33}$

Ha sido, a mi juicio, un persistente yerro de casi todos los intérpretes de Hegel leer el resto de su producción filosófica bajo el ángulo en que se coloca el tal texto de la Differenz, de suerte que se admite ya casi como lugar común que la relación de Hegel con Schelling consiste en que el sistema de aquél no es sino la consumación o el llevar hasta el límite de su cumplimiento el sistema de la identidad que éste habría dejado a la mitad. El hegeliano, según esto, no sería sino un sistema schelliniano radicalizado, completado de cabo a rabo: Hegel sucesor de Schelling. Ha sido oceánica la cantidad de veces que escuché a profesores y que leí en historias de la filosofía que Hegel no habría hecho otro cosa que superar, en nombre del principio de identidad de Schelling, la escisión o desigualdad aún presente, debida a un déficit de subjetividad, en el pensamiento de Schelling. ¿Quién no conoce el esquema según el cual el idealismo alemán incluye tres tipos, cada uno sucesivo del anterior, según un esquema que va de la menor a la mayor identidad: el idealismo subjetivo de Fichte, el objetivo de Schelling y el absoluto, la síntesis de uno y otro, de Hegel?

Sucede que en realidad la ruptura entre Schelling y Hegel radica, por debajo del tema de la intuición, en que éste rechaza que el principio de identidad sea el punto de partida (y de llegada) de la ciencia. Slavoj Žižek advierte:

La figura habitual según la cual Hegel admite la heterogeneidad, la diferencia, la escisión, etc., pero que no las deja subsistir más que conteniéndose dentro del marco de la identidad, esta figura -cuya forma es precisamente aquella de yo sé perfectamente (que Hegel afirma la escisión, que él hace estallar la identidad), pero sin embargo (reduce la diferencia al marco de la identidad)- es pues fundamentalmente errónea: no es más que con la sintesis que la diferencia es verdaderamente reconocible. ${ }^{34}$

${ }^{33}$ En G.W.F. Hegel Hauptwerke 1. Jaener kritische Schriften, 1999,Hamburg, Felix Meiner, p. 63.

${ }^{34}$ Le plus sublime des Hysteriques. Hegel passe, 1988, Paris, Point Hors Ligne, p. 90. 
¿Pero no está acaso Žižek sosteniendo en el segundo hemistiquio, después de la adversativa, exactamente lo mismo que afea en el primero? ¿No es decir que sólo en la síntesis, que en la identidad, es reconocible la diferencia, exactamente lo mismo que decir que la diferencia sólo subsiste dentro del marco de la identidad? No, no es lo mismo, porque cuando Hegel afirma que la diferencia no es reconocible más que con la identidad, no está defendiendo la idea de que las diferencias sean escisiones deducidas del absoluto. La lógica de Hegel no es la misma que la de Schelling.

7. Sabemos que Schelling rechazará su propia filosofía de la identidad, en nombre de lo que él mismo llamara "filosofía positiva"; empero, lo hará en virtud de la misma concepción de lógica que supuso en su período de "filosofía de la identidad". Hegel, por su parte, se apartará del punto de vista de la filosofía de la identidad precisamente por la misma razón por la que también rechazará la "filosofía positiva" de Schelling, por haber rechazado de cuajo la concepción de lógica que éste siempre conservó.

De acuerdo con Schelling, el punto de partida de la ciencia, no puede ser él mismo científico, pues hay algo en él, en cuanto que es el absoluto, que se sustrae por completo a la razón, a la lógica, algo que reside soterradamente debajo del fundamento racional y que ha de permanecer pre-lógicamente determinado. Previo al sistema de la ciencia, entendido como sistema de identidad, Schelling cree ver "al Señor del Ser", libre de todo sí mismo, y por ende libre de toda relación de identidad; relación de identidad que, por su parte, no tendrá otro estatus ontológico que ser la obra primera y remedo deficitario del acto creador del tal Señor del Ser, y ya no más principio originario. La ciencia, pues, piensa Schelling, "es el proceso de repetición interna e imitativa de aquel grandioso proceso secreto de toda vida desde su silencioso inicio hasta el presente, y hasta el más remoto futuro". ${ }^{35}$

Hegel, en cambio, no admitirá, ya desde la publicación de la Fenomenología, esta franca incursión dentro de la espesa selva de

${ }^{35}$ Die Weltalter. Fragmente. In der Urfassungen von 1811 und 1813, 1979, München, Biederstein und Leibniz Verlag, p. 188. 
JOSÉ ANTONIO PARDO

la irracionalidad gnóstica. Lukács escribe que "la lucha de Hegel contra Schelling era la lucha entre el desarrollo de la dialéctica y la evasión de ella, la huída hacia el irracionalismo". ${ }^{36}$ Tiene el pensador húngaro media parte de razón, porque la verdad es que la dialéctica nunca fue la preocupación fundamental de Hegel. Cualquiera que lo lea podrá encontrar sin dificultad que el momento dialéctico de su argumentación, es decir, el momento de la refutación, nunca es el definitivo, que siempre está enderezado hacia el momento especulativo, que es el verdaderamente conclusivo: "La dialéctica tiene un resultado positivo, porque tiene un contenido determinado o porque su resultado verdaderamente no es el vacio, nada abstracta, sino la negación de la conciencia determinada, es la nada que está contenida en el resultado, pues no es una nada inmediata, sino un resultado". ${ }^{37}$ Como bien señala el que estimo ser el mejor y más diáfano exegeta de la filosofía hegeliana: "Los comentaristas, sobre todo los marxistas, se fueron tras la finta: creyeron que la dialéctica era importante en sí misma, cuando en realidad lo único importante para Hegel es demostrar que todos los conceptos quieren decir el espíritu". ${ }^{38}$ A Hegel le preocupa la racionalidad, el no dejar que se cuelen aseveraciones gratuitas, que la ciencia se justifique científicamente, que la razón se determine racionalmente, y no mediante expedientes retóricos, alusiones a experiencias inenarrables, ni a rústicas apelaciones a la autoridad (aunque sea la autoridad de un científico o de algún presunto "dato duro"). Y es en virtud de la racionalidad que reconoce que el principio de identidad flaquea como fundamento absoluto: carece de justificación, y por ende, todo sistema fundado en él será irremisiblemente un sistema dogmático, pura mitología edificada sobre el puro arbitrio.

Escribe Hegel: Schelling "ha empleado, como Spinoza, un método geométrico: establece axiomas [tales como el principio de identidad] y luego teoremas, sobre los cuales corre la carga de la prueba [...] Pero

${ }^{36}$ El Asalto a la Razón. La trayectoria del irracionalismo desde Schelling hasta Hitler, 1968, Barcelona, Grijalbo, trad. de Wenceslao Roses.

${ }^{37}$ G.W.F. Hegel, Enzyklopädie der philosophischen Wissenschaften I, § 82, op. cit., pp. 176-177.

${ }^{38}$ Porfirio Miranda, Hegel tenía razón. El mito de la ciencia empírica, 1989, México, UAM, p. 177. 
ese método no tiene verdaderamente ningún uso en filosofía". ${ }^{39}$ A pesar de esta explícita y documentable repulsa al método axiomático como instrumento filosófico, Schelling, ya desde sus cursos en Munich, enseñó, en efecto, que el sistema de Hegel era uno de tipo axiomático, y por ende, su único criterio, el principio de identidad o "consistencia lógica", y su único mecanismo, la deducción tautológica de toda determinación a partir del concepto de ser, el cual a su vez es definido como lo igual a sí mismo. Según Schelling, cosa que creyeron sin remilgos Feuerbach, Kierkegaard y otros, la filosofía de Hegel era, con todas las veras, filosofía de la identidad [Identitätsphilosophie] ${ }^{40}$ panteísmo spinozista.

Nicolas Rescher advierte que el sistema hegeliano no es de tipo axiomático. Inclusive acuña la expresión "inversión hegeliana" para definir el punto en que Hegel se separa de la axiomática euclideana. Dicha inversión consiste, dice Rescher, en "el pasaje de la pretendida implicación cognoscible $\rightarrow$ sistematizable, o su formulación afín: (presumiblemente) conocido $\rightarrow$ (debidamente) sistematizado, a la implicación inversa: (debidamente) sistematizado $\rightarrow$ (presumiblemente) conocido". ${ }^{41}$ Mientras que la axiomática euclideana supone para sus axiomas, como en Aristóteles en el texto citado más arriba, la calidad de "verdades primitivas (no fundadas, inmediatas, intuitivas)", "el programa coherentista de epistemología implementa la inversión hegeliana adoptando el modelo de red de sistematización cognoscitiva [...] En este enfoque, el patrón de aceptabilidad de tesis no es su derivabilidad deductiva a partir de alguna base sacrosanta, sino su conectabilidad sistemática de unas tesis con otras". ${ }^{42}$

En parte Rescher tiene razón: Hegel, en efecto, rechaza explícitamente la aceptación de axiomas como "verdades sacrosantas". La demostración axiomática "toma un camino que comienza en cualquier parte, sin que se sepa aún en qué relación está con el resultado que se ha de obtener. Su marcha toma estas determinaciones y relaciones y no le hace caso

${ }^{39}$ G.W.F. Hegel, Vorlesungen über die Geschichte der Philosophie III, 1979, Frankfurt, Suhrkamp, p. 437.

${ }^{40}$ Geschichte der neueren Philosophie. Münchener Vorselungen, en Schelling Werke V, op. cit., p. 208.

${ }^{41}$ Sistematización cognoscitiva, México, Siglo XXI, trad. de Carlos Rafael Luis, p. 66.

${ }^{42}$ Ibid., p. 68. 
a otras, sin que se entere uno de manera inmediata de a cuál necesidad se ajusta esta elección; [sucede que] este movimiento está regido por un fin ajeno [a la demostración]". ${ }^{43}$ Sin embargo, Hegel rechaza también el "criterio coherentista de verdad".

Albert Einstein explica que es ilusorio e innecesario imaginar que un axioma, en geometría, es una verdad primitiva, puesto que la verdad es un asunto irrelevante para cualquier sistema axiomático, como lo es el de Euclides. Me parece que la distinción de Rescher entre modelos axiomáticos y modelos de red es nula, pues uno, tanto como el otro, operan en virtud del concepto coherentista de verdad. La atribución de verdad a un axioma, independientemente de la coherencia suscitada desde éste, es decir, la suposición de que el axioma corresponde a la realidad, rebasa el marco de lo que estrictamente pertenece a un sistema axiomático. Es verdad que del axioma se deducen analíticamente, como desde un fundamento, teoremas y proposiciones, pero un axioma, en cuanto tal, lo es sólo en la medida en que desde él es posible satisfacer la exigencia de consistencia, y no porque sea una verdad inmediata. Ahora bien, la exigencia de consistencia, al margen de la verdad, es justo el principio de identidad que Schelling quiere ver campeando como fundamento absoluto del sistema hegeliano.

Schelling declara incontables veces que en la filosofía de Hegel se confunde la lógica con la ontología, de modo que a la postre dicha filosofía se vuelve negligente en relación con la verdad: "la filosofía de la identidad trata sólo de un puro qué de la cosa, pero nada dice de la existencia en acto [wirkliche Existenz]". ${ }^{44}$ Etienne Gilson repite casi literalmente la interpretación de Schelling, lo mismo que su crítica al Hegel de tal interpretación: "Hegel puede asumir un tema metafísico cualquiera y sacar de él un mundo con la misma facilidad y la misma belleza a veces con que Bach puede escribir una fuga; pero Bach está en su lugar, porque el fin del arte es crear, mientras que Hegel comete un grave error, porque el fin de la ciencia es conocer. Igual que la ciencia, la ciencia no puede ser sistema, porque todo pensamiento sistemático

${ }^{43}$ G.W.F. Hegel, Phänomenologie des Geistes, 1986, Frankfurt, Suhrkamp, p. 44.

${ }^{44}$ Geschichte der neueren Philosophie, op. cit., p. 128. 
comienza por asumir". ${ }^{45}$ Gilson, desde luego, confunde sistema con sistema axiomático, en tanto que Schelling, quizá maliciosamente, adultera gravemente el pensamiento de Hegel.

Hegel sabe perfectamente, y lo declara, que la verdad no es relevante a la hora de levantar un sistema axiomático; que la realidad en acto (o existencia, tal como la llama Schelling) no le incumbe a un sistema de identidad; que en un sistema tal la diferencia queda diluida como diferencia. Pero sucede que el suyo no es ningún sistema de identidad. Hegel, anticipándose a Kierkegaard y a Schelling mismo, escribe que los sistemas axiomáticos actúan sobre un elemento irreal [unwirkliche Elemente], inactual o inexistencial, en el cual "sólo se da lo verdadero inactual [unwirkliches Wahres], esto es, proposiciones muertas, fijas [...] Además, al andar sobre ese principio y elemento [el elemento irreal] -y en eso descansa lo formal de la evidencia matemática-el saber sólo sigue la línea de la igualdad [...] pues es sólo la magnitud, la distinción inesencial, de lo que la matemática se ocupa". ${ }^{46}$

Hegel insiste en que la ciencia debe expresarse de manera sistemática, pero esto no supone que deba deducirse conforme a un sistema axiomático. A fuerza de ir absorbiendo el vapor de las habladurías, el medio académico ha quedado convencido, sin crítica de por medio, de manera irracional y dogmática, de que el modo sistemático es excesivamente pretensioso e inadecuado. Empero, ese convencimiento se nutre de los engendros de su propia imaginación. Ser sistemático no significa, por lo menos en Hegel, querer deducir todo a partir de una verdad primitiva, ni de sofocar las diferencias con tal de ganar una figura rotunda. Ser sistemático no implica plegarse a la voluntad de reducir todo a la identidad, sino dar razón de todo, de la identidad y de la diferencia, y reconocer que sólo en ese dar razón de una y otra, ésta y aquélla quedarán definidas concretamente como identidad y como diferencia.

Lo que Žižek en el texto antes citado quiere decir cuando escribe que "sólo en la síntesis la referencia es reconocible" es que sólo mediante argumento concluyente (que no necesariamente consiste en p. 284.

${ }^{45}$ El ser y la esencia, 1971, Buenos Aires, Desclée de Brower, trad. de Leandro de Sesma,

${ }^{46}$ Phänomenologie des Geistes, pp. 44-45. 
JOSÉ ANTONIO PARDO

razonamiento tautológico, ni en reducción de lo diferente a lo igual) la diferencia queda definida como diferencia de verdad, como diferencia real, y no como simple nominación vacía. El principal defecto de las filosofías de la diferencia que pulularon durante el siglo XX, desde Levinas y Derrida hasta Enrique Dussel, fue que se conformaron con martillar propagandísticamente las palabras "otro", "alteridad", "diferencia", etc., pero sin tomarse la molestia de demostrar la realidad del significado de dichas palabras. En cambio les bastó con haberlas definido por decreto y a punta de negaciones, negaciones de una identidad cuya definición tampoco les mereció atención, pues supusieron que la alusión al solo nombre de Hegel completaba ostensivamente el significado de "identidad".

8. No es inusual que los hegelianos defiendan su postura contra los embates de las críticas de los posthegelianos señalando que éstas desconocen el verdadero sentido de la filosofia hegeliana, que esas críticas no afectan tanto a Hegel cuanto a la imagen distorsionada de Hegel que los propios críticos han forjado en su cabeza. De hecho, en este mismo escrito he intentado mostrar que el Hegel de Kierkegaard, Feuerbach, Russell y de tantos otros, no es el Hegel real, sino el fruto de una distorsión efectuada por Schelling. La idea de un Hegel sucesor, o mejor dicho secuela, de Schelling en la línea de la filosofía de la identidad, de la mera posibilidad lógica al margen de la existencia, se debe, cierto, a un escrito del propio Hegel, pero redactado cuando éste aún carecía de pensamiento propio, o como dice Žižek, previo a cuando Hegel se transformó en Hegel, pero mucho más que a esto, a la propaganda schelliniana.

Sin embargo, que las críticas no atinen al Hegel de veras, no implica que entre éste y sus críticos no exista un profundo desacuerdo. Los posthegelianos han hecho de Hegel un espantapájaros sobre el cual descargar su violencia. Las acusaciones que los posthegelianos hacen a Hegel son infundadas y casi fruto exclusivo de difamaciones, pero aun así, Hegel no es un posthegeliano. Hegel no es ese dragón panteísta, panlogicista, totalitario y desatento a la diferencia, pero tampoco es un teórico de la différance, ni vocero oficioso del "otro" o de la alteridad. Tampoco es un "justo medio" entre filosofías de la identidad y de la diferencia. Un pensamiento como el de Levinas genera repulsa en 
un hegeliano no porque el filósofo lituano acentúe en exceso la importancia del otro, sino porque la alusión a dicho otro carece de contenido. La filosofía de la identidad también genera rechazo, pero no porque dicha filosofía no incluya la diferencia, sino también porque su alusión a la identidad es vacía.

Heidegger reconoció pronto que Schelling era un testigo de lujo para acreditar la tesis del olvido del ser y de la negligencia de la filosofía para advertir la diferencia ontológica. Gustav Siewerth, por su parte, se solidariza con Heidegger hasta cierto punto: le da asenso a la opinión de éste, según la cual hay un olvido del ser y nula sensibilidad hacia la diferencia, pero los circunscribe no fuera del ámbito de la filosofía moderna, pues en cambio, afirma categóricamente que Tomás de Aquino no incurre en ese olvido, que su sistema no es ningún "Identitätssystem", ${ }^{47}$ sino un auténtico sistema de la diferencia cuya posibilidad (que parece problemática en virtud de que sistema y diferencia parecen términos antitéticos) radica en el recurso a la analogía. Viene al caso esto porque Schelling critica a Hegel exactamente, tal como quedó ya sugerido en un texto de aquel filósofo citado anteriormente, en los términos y con los mismos términos de la distinción escolástica entre esencia y existencia. El tema de la filosofía de la identidad pasa por el de la distinción esencia y existencia.

Schelling, ya como sucesor de Hegel en la universidad de Berlín, aunque desde antes, (mal) interpretaba la filosofía de su antiguo amigo calificándola de "filosofía negativa". Sostiene Schelling que el punto de partida de la ciencia debe ser la existencia en acto, pero que Hegel en cambio comienza con lo lógico, que como tal no es más que "lo meramente negativo de la existencia [das bloss Negative der Existenz]" ${ }^{48}$ Por lo mismo, por haber decidido partir de lo meramente negativo, lo positivo, que es lo existencial y ontológico, se le mostrará huidizo siempre: "la filosofía negativa sólo se ocupa de la posibilidad [Möglichkeit], pues conoce todo en el puro pensamiento como independiente

${ }^{47}$ Cfr. Das Schicksal der Metaphysik von Thomas zu Heidegger, 1959, Freiburgi, Br., Johannes Verlag Einsiedeln, p. 23.

${ }^{48}$ Schelling, ibid., p. 164. 
JOSÉ ANTONIO PARDO

de toda existencia". ${ }^{49}$ Según Schelling, pues, la filosofía de Hegel es una filosofía apriorística, que fundada en la pura identidad, se ocupa sólo del ser posible, cuyo criterio es precisamente la satisfacción del principio de identidad, pero no del ser en acto, del ser real. Enseguida un largo trozo de un escrito de Schelling:

La razón, en cuanto se rige por sí misma, se hace objeto de sí misma, encuentra en sí el prius o, lo que es lo mismo, el sujeto de todo ser, y en esto tiene el medio o más bien el principio de un conocimiento a priori de todo ente [seyende]. Pero ahora se pregunta qué es aquello que es de esta manera, es decir, qué es todo ente conocido a priori. ¿Es la esencia, la especie [die Sache] del ente, o es que es [oder das es ist]? Aquí es preciso advertir que en toda realidad hay que discernir dos cosas, pues son dos cosas completamente distintas saber qué es un ente (quid sit) y saber que es (quod sit). Aquello -la respuesta a la pregunta: qué es- hace que me percate de la comprensión de la esencia de la cosa [gewährt mir Einsicht in das Wessen des Dings], o hace que yo entienda la cosa, que tenga el entendimiento o concepto de ella, o que la tenga en el concepto. Pero lo otro, la comprensión de que es, el mero concepto no hace que me percate de ello, es algo que rebasa el concepto, es la existencia [Existenz]. ${ }^{50}$

Schelling en realidad confunde las cosas convenientemente para su causa. Es legítimo llamar a la de Hegel filosofía negativa en el sentido de que, en efecto, Hegel no admite que a lo positivo, en el sentido de lo dado, le quepa el honor de ser punto de partida y tribunal supremo de la ciencia. Pero Hegel está lejos de admitir que la existencia sea ajena al concepto. Por otra parte, el sentido que tiene en Hegel partir de lo negativo no es partir de la posibilidad. Lo negativo, en Hegel, no es lo negativo de la existencia o del ser en acto, sino lo negativo de lo dado. Es decir, hay que admitir el sistema de Schelling en general, y en particular que captar que algo existe sea lo mismo que experimentarlo sensorialmente o experimentarlo dado positivamente -cosa a la cual no estamos obligados sin más-, para inferir que negar lo dado es

${ }^{49}$ Schelling, Philosophische Einleitung in die Philosophie der Mythologie oder Darstelung der reinrationalen Philosophie, en ibid., p. 745.

${ }^{50}$ Der Philosophie der Offenbarung, en op. cit., VI, pp. 57-58. 
lo mismo que negar la existencia y, por ende, lo mismo que aferrase a la pura posibilidad, a la sola esencia.

Parece que Schelling expone fielmente a Hegel cuando escribe que, según éste, la ciencia debe comenzar desde el ser y que tal ser es lo indeterminado, la vaciedad total. Aunque añade infielmente cosas por su cuenta cuando dice que "entrambos, ser y nada, son sólo algo en potentia", ${ }^{51}$ y que por lo mismo, Hegel sólo se ha de ocupar, determinado por su punto de partida, del mero ser posible. Schelling, vuelvo a lo mismo, enseña que el punto de partida de Hegel es una tautología vana de la cual ha de deducir todo, y que por lo mismo es incapaz de advertir nada fuera de lo que Leibniz llamaba "posibilidad lógica". Pero no quiere darse por enterado de que es el propio Hegel quien declaró anteriormente a Schelling que ese ser es tautológico, y por ende, nada. Cuando Hegel escribe que "el ser, lo inmediato indeterminado, de hecho no es nada, no es ni más ni menos que nada", ${ }^{52}$ en realidad está, como señala Porfirio Miranda, "haciendo chunga", ${ }^{53}$ está argumentando en contra de quienes sostienen que el ser es algo inmediatamente dado, está señalando que esa palabra, "ser", que con tanta celeridad se agita cuando se pide un justo punto de partida, no significa nada. Por esto, en un manual de introducción a la lectura de la Ciencia de la Lógica encontramos escrito que "ser", "en sentido estricto, no merece el título de concepto". 54

9. El comienzo de la ciencia no es el ser vacío, sino la demostración dialéctica (por refutación) de que el ser es vacío. "El devenir [Das Werden] es el primer pensamiento concreto [konkrete Gedanke] y por ende lo primero que se entiende, el primer concepto [erste Begriff], mientras que ser y nada son abstracciones vacías" ${ }^{55}$ Ahora bien, un ejemplo de dicho devenir, de acuerdo con Hegel, es Heráclito, pues con él

${ }^{51}$ Geschichte der neueren Philosophie, en op. cit., p. 204.

${ }^{52}$ Wissenschaft der Logik I, p. 83.

${ }^{53}$ Op. cit., p. 89.

${ }^{54}$ J. Birad, D. Buvat, J.F. Kervegan et al., Introduction à la lecture de La Science de la Logique de Hegel, 1981, Paris, Aubier, p. 47.

${ }^{55}$ Enzyklopädie $§ 88$ (Zusatz), p. 192. 
JOSÉ ANTONIO PARDO

"tenemos un ejemplo de verdadera refutación de un sistema filosófico a través de otro, la cual refutación consiste justo en este punto, en que demuestra el principio de la filosofía refutándose según su propia dialéctica". ${ }^{56}$

De esa refutación se siguen otras determinaciones, y es justo la manera en que se siguen lo que constituye la esencia de la lógica hegeliana, del concepto hegeliano de demostración. No es que del ser vacío se deduzcan analíticamente todo el resto de las categorías. Si fuera así, en efecto, tendría razón Schelling, porque entonces ninguna de las categorías podría dar cuenta del existir; de hecho, la misma categoría existir, como en el caso de Wolff, no se distinguiría prácticamente en nada de la de posibilidad, por ser aquélla mera deducción tautológica de ésta. La palabra "ser", según su uso en ontología fundamental y regida por la dialéctica propia de ese uso, se refuta en la medida en que se demuestra vana, lo contrario de lo que pretende. "La impaciencia que sólo quiere encontrarse a sí misma encima de lo determinado, llámesele a éste comienzo, objeto, infinito o de cualquier otra manera, y que además quiere encontrarse inmediatamente en lo absoluto, no tiene delante de sí como conocimiento sino la negatividad vacía, el infinito abstracto, -o un absoluto que se ha querido nombrar [gemeinen], que únicamente se ha querido nombrar, [...] pero que no se lo ha captado". ${ }^{57}$ Pero esa refutación inmediata, empero, supone, por mor de inteligibilidad, la admisión de unos principios y categorías que se irán ganando a la postre, según vaya avanzando el proceso.

La refutación inicial sugiere una forma de escepticismo, una forma de escepticismo en relación con la posibilidad de definir un punto de partida adecuado para la ciencia. Ahora bien, como señala Jonathan Dancy, sólo el escepticismo que guarda la forma de conclusión argumentativa es del tipo que vale la pena considerar: "El escepticismo en su forma más interesante depende siempre de un argumento", ${ }^{58}$ y por lo mismo de ciertas premisas. Pero esas premisas no se suponen, sino que

${ }^{56}$ Ibid., p. 193.

${ }^{57}$ G.W.F. Hegel, Wissenschaft der Logik II, p. 571.

${ }^{58}$ Jonathan Dancy, Introducción a la epistemología contemporánea, 1993, Madrid, Tecnos, trad. de José Luis Prades, p. 21. 
de hecho se infieren o se ponen reflexivamente como condiciones de posibilidad de la refutación admitida en el principio. Karl-Otto Apel demuestra la existencia de un fundamento último para la ciencia, mediante una estrategia argumentativa que consiste en señalar cómo la refutación de la posibilidad de hallar racionalmente un fundamento último de la ciencia, refutación llamada por Hans Albert “trilema de Münchhausen”, supone ya la admisión de un fundamento sobre el cual descansa la validez de la refutación. ${ }^{59}$ Pero, insisto, la admisión de ese fundamento no es una suposición, sino una inferencia cuya condición es la admisión del carácter refutativo del trilema. Pero además, la admisión del carácter refutativo del trilema es la expresión racional del escepticismo o la expresión del único escepticismo que no es, de hecho, una afirmación dogmática $\mathrm{y}$ arbitraria.

Hegel en realidad sostiene que el escepticismo es el punto de partida de la ciencia, pero no el escepticismo dogmático, sino el escepticismo que depende de un argumento; pero de un argumento que es una refutación, cuyas premisas no se suponen sino que se infieren al final como condiciones de intelección determinada y de validez de la misma refutación, del punto de partida. A su vez, la refutación se admite, pero no porque sí, sino porque de no admitirse, el escepticismo adoptado, escepticismo cuyo aguijón es el que espolea al pensamiento, no pasaría de ser una postura caprichosa e irracional, postura que es la que se quiere evitar cuando no se admite cualquier tipo de punto de partida que se le ocurra a quienquiera. Escribe Hegel:

Así, de esta manera cada paso del proceso en el determinar ulterior, en tanto que se aleja del comienzo indeterminado, es también un acercamiento de vuelta [Rückannäherung] a ese mismo comienzo, de modo que lo que primeramente parece distinto, la fundamentación involutiva [rückwärtsgehende Begründen] del comienzo y la ulterior determinación procesual [vorwärtsgehende] del mismo, caen una en la otra y son lo mismo. ${ }^{60}$

${ }^{59} \mathrm{Cfr}$. "El problema de la fundamentación filosófica última a la luz de una pragmática trascendental del lenguaje", en Dianoia 21, 1975, México, Instituto de Investigaciones Filosóficas, UNAM, trad. de Bernabé Navarro.

${ }^{60}$ Ibid., p. 570. 
JOSÉ ANTONIO PARDO

El punto de partida se justifica no por medio de aseveración dogmática, sino por refutación; no como deducción de ciertas premisas presupuestas, sino mediante la generación inferencial de dichas premisas como condiciones de posibilidad de la refutación. A su vez, este proceso que Žižek denomina "performatividad retroactiva", ${ }^{61}$ es lo que define la específica y rigurosa actividad esencial del sujeto.

La necesidad lógica es la exigencia de que un concepto tenga significado y se entienda. La implicación entre conceptos es lo que tanto la lógica tradicional como la de conjuntos pasan por alto; pero esa implicación es la que permite que haya verdadera inferencia de algo nuevo, de algo que efectivamente acrecienta nuestro conocimiento y no se reduce tautológicamente a lo ya dicho; lo que ya estaba dicho no se sigue, porque ya estaba [...] En cambio, la lógica de Hegel empieza con el concepto de ser [que se delata nulo en la refutación], y a base de exigir que tenga significado y se entienda [el ser refutado o negado (aufgehoben) y el proceso mediante el cual se refutó], desemboca en un contenido nuevo. ${ }^{62}$

10. Sucede que Schelling asume sin mayor remilgo la concepción de lógica que Hegel intenta reformar, sin ofrecer ninguna réplica o contraargumento a la concepción hegeliana. Incluso parece que ni siquiera advierte que exista una tal lógica hegeliana y una tal crítica de Hegel a la lógica escolástica, a la lógica fundada en el solo principio de identidad. Schelling admite, como si Hegel no hubiese escrito contra ella, una concepción de lógica tal como la expresada por Tomás de Aquino en el siguiente texto:

Lo lógico, pues, considera el modo de predicar, y no la existencia de las cosas [et non existentiam rei]. De donde resulta que cualquiera cosa que sea respondida a la pregunta qué es [ad quid est], dirá algo que recaiga sobre lo que es: ya aquello que sea intrínsecamente, como materia y forma, ya aquello que sea extrínsecamente, como agente y fin. Pero los filósofos, que investigan la existencia de las cosas, del fin o del agente, no incluyen

${ }^{61}$ Cfr. op.cit., p. 32.

${ }^{62}$ Porfirio Miranda, op.cit., p. 192. 
tal existencia bajo aquello que es el ser [quod quid erat esse], pues la existencia es extrínseca. De modo que si decimos que casa es algo que protege del frío y del calor, lo hemos de decir lógicamente, como significando lo que es el ser, y no según la consideración de los filósofos. ${ }^{63}$

Es rigurosamente cierto que por medios analíticos no se puede demostrar la existencia de nada, que ningún silogismo puede ofrecer como conclusión la existencia de algo, salvo que dicha existencia se suponga ya en las premisas, y además conocida por otro medio que el lógico (según la concepción escolástica de lógica). Pero ¿cuál es este medio, que no es el lógico, por el cual se cae en la cuenta de que algo existe? Según Schelling, pero también según cierto tomismo: la intuición empírica ${ }^{64}$ ¿Pero es verdad que por medio de los sentidos captamos que algo existe, de modo que el significado de existir sea "ser posible objeto de la experiencia empírica"? Admito que de la mera posibilidad no se puede inferir la existencia, pero no concedo que se conozca que algo exista porque se lo experimente empíricamente.

Hume escribe: "Aunque toda impresión o idea que recordamos sea considerada como existente, la idea de existencia no se deriva de ninguna impresión particular", ${ }^{65}$ lo cual es verdad. Pero a partir de esto pretende concluir, por medio de un dilema, que la idea de existencia es exactamente la misma que la de impresión sensible. Esto último es insostenible. De ser verdad que no se distinguiese la idea de existencia de la de cualquier idea originada por impresión sensible, el hombre sería incapaz de discriminar los cien taleros posibles de los cien taleros existentes de que habla Kant. Cierto, Kant sostiene que es imposible trazar ninguna línea divisoria entre unos y otros apelando al solo concepto de cien taleros, ${ }^{66}$ que dicha línea queda trazada en la medida en que el concepto de los segundos está unido a las condiciones materiales de la experiencia, es decir a la sensación. ${ }^{67}$

${ }^{63}$ S. Thomae Aquinatis, In XII Libros Metaphysicorum Expositio, 1658, Marietti, 1964, Torino-Roma, lectio 17, p. 396.

${ }^{64}$ Pedro Descoqs, Thomisme et Scolastique-à propos de M. Rougier, en Archives de philosophie, 1935, Paris, Beauchesne, vol. V, cuaderno 1, p. 112.

${ }^{65}$ Treatise of Human Nature, 2004, Londres, Jonathan Bennett, I, ii, 6, p. 37.

${ }^{66}$ Kritik der reinen Vernunft, B627, p. 234.

${ }^{67}$ Ibid., B 265, p. 296. 
JOSÉ ANTONIO PARDO

Kant admite la distinción entre el contenido del concepto, que corresponde, según Schelling, a la esencia, y su verificación efectiva por medio de la intuición sensible. Pero de acuerdo con Hume, el contenido del concepto y su verificación efectiva (no la posibilidad de verificación del verificacionismo semántico) son lo mismo. De este modo, a la postre, resultará imposible, si permanecemos fieles a la epistemología empirista de Hume, discriminar los taleros reales de los posibles. En efecto, el concepto de posibilidad también carece de "impresión particular" distinta, pero en su caso no cabe argüir, como en el de existencia, que el de posibilidad tuviese el mismo contenido que el de impresión sensible, porque en ese caso, y dado que el contenido del concepto de existencia es también el de impresión sensible, habría que admitir, por simple transitividad, un absurdo: lo posible es lo mismo que lo existente.

Hegel mismo ofrece esta reducción al absurdo, he aquí la conclusión: "La realidad en acto como tal es posible; está en identidad positiva e inmediato con lo posible; pero lo posible se ha determinado como mera posibilidad; de suerte que lo real en acto también está determinado como un meramente posible". ${ }^{68}$ Sólo en la idea el pensamiento se muestra capaz de definir y distinguir concretamente lo real de lo posible. He aquí de nuevo el sentido de la afirmación de Žižek, citada con antelación. Fuera de la idea, realidad y posibilidad quedan disueltas en una unidad indiscernible, de modo que su distinción queda en una mera distinción posible, una distinción a concretarse en un futuro indefinido.

Hegel no desatiende la existencia, ni se contenta con contemplar el mundo sub specie posibilitatis. Simplemente reconoce que usar la palabra "existencia" supone conocer el significado de ésta, y que este significado sólo cabe obtenerse discursivamente. No se trata sólo de que Schelling haya difamado a Hegel, sino de que dejó canonizada por obra de su autoridad de gran filósofo, una vía filosófica que, corriendo bajo la promesa de lo concreto, se ha quedado en realidad atascada en la abstracta indeterminación del gesto de señalar algo con el dedo, en la mera posibilidad de que alguien entienda qué cosa es lo que señala ese dedo.

${ }^{68}$ Wissenschaft der Logik II, p. 205. 